Ensino, Saúde e Ambiente - V 7 (1), Edição Especial, maio de 2014

\title{
A CONSTRUÇÃO DE UM DICIONÁRIO DE CINEMÁTICA E A RESOLUÇÃO DO PROBLEMA DO MOVIMENTO DA ARRUELA - APLICANDO A ARGUMENTAÇÃO NO ENSINO DE FÍSICA \\ BUILDING A KINEMATIC DICTIONARY AND THE PROBLEM OF THE WASHER MOTION RESOLUTION - APPLYING THE ARGUMENT IN PHYSICS EDUCATION
}

\author{
Tiago Destéffani Admiral ${ }^{1}$, Dr. Carlos Roberto Pires Campos ${ }^{2}$, Leonardo Salvalaio \\ Muline $^{3}$ \\ ${ }^{1}$ UENF/ Programa de Doutorado em Ciências Naturais - CCT, tiago.admiral@iff.edu.br \\ ${ }^{2}$ IFES/ Programa de Mestrado em Ensino de Ciências - Educimat, carlosr@ifes.edu.br \\ ${ }^{3}$ FIOCRUZ/ Programa de Doutorado em Ensino em Biociências e Saúde, leonardosalvalaio@ @mail.com
}

\section{RESUMO}

É público e notório que a tecnologia permite aos alunos o acesso às informações, de diferentes maneiras. O que se torna um desafio para o educador, que é o principal agente responsável por gerenciar essas informações para que se tornem conhecimento. O método de ensino baseado em apresentar informações perde espaço nesse contexto, demandando uma prática educativa que considere o aluno como um ator social que possui um conhecimento prévio, e historicamente construído. Esse artigo analisa dois episódios de Ensino de Física em que foi adotada a postura metodológica PBL (Problem-Based Learning), associada à análise argumentativa, para descrever $\mathrm{o}$ aprendizado de conceitos sobre cinemática. Com isso, conseguimos compreender melhor de que forma a argumentação pode auxiliar no aprendizado de um novo conceito científico. Trata-se de uma pesquisa qualitativa, realizada em uma turma de primeiro ano do Ensino Médio Integrado, na cidade de Campos dos Goytacazes - RJ.

Palavras-chave: ensino de física, PBL, prática argumentativa, mudança conceitual.

\begin{abstract}
It is well known that the increasing the technology allows students to access information in different ways. This becomes a challenge for the teacher, which is the main responsible agent for managing this information in order for it to be turned into knowledge. The teaching method based on present information loses ground in this context, requiring a pedagogical practice that considers the student as a social actor who has a prior knowledge, historically constructed. This article examines two episodes of Physics Teaching that was adopted the methodological approach PBL (Problem-Based Learning), associated with argumentative analysis to describe learning concepts about kinematics. With that, we come to understand better how the argument can assist the construction of a new scientific concept. This research was qualitative in nature and was conducted with a class of first year of high school in the city of Campos dos Goytacazes - RJ.
\end{abstract}

Key words: physics teaching, PBL, argumentative practice, conceptual change. 
Ensino, Saúde e Ambiente - V 7 (1), Edição Especial, maio de 2014

\section{INTRODUÇÃO/FUNDAMENTAÇÃO TEÓRICA}

Um aspecto importante do processo de ensino aprendizagem reside na linguagem, mais precisamente, na dimensão argumentativa da linguagem. É por meio da argumentação que os conceitos científicos são construídos e da mesma forma podem ser aprendidos. Para NASCIMENTO e VIEIRA (2008) a linguagem pode ser considerada como mediadora entre o homem e a natureza, por meio da qual ocorrem os processos de interação social, de aprendizagem e de apropriação do conhecimento, em especial do conhecimento científico. Entre os diferentes discursos possíveis na linguagem, a argumentação se mostra como dos de maior possibilidade de promover a aprendizagem.

Nesse processo, as práticas argumentativas em sala de aula se mostram excelentes instrumentos. VILLANI (2002) indica que, apesar da pouca utilização desse tipo de prática argumentativa na escola, ela apresenta uma série de benefícios ao aprendizado, principalmente no que diz respeito à participação do aluno durante as aulas. De acordo com o autor, fazer com que os alunos exercitem a argumentação incentiva tanto à interação intra-sala-de-aula quanto favorece a construção mais segura dos conceitos desenvolvidos, isso porque, ao desenvolver um argumento, o aluno deve, a princípio, pensar a respeito das premissas que irão fundamentar sua fala. Nessa operação cognitiva, a experiência com o discurso utilizado na ciência tem o condão de transformar a forma de o aluno com o mundo se relacionar. $\mathrm{O}$ fato é que melhorar a habilidade argumentativa dos alunos é importante no sentido que a argumentação é utilizada em diversos aspectos da vida, em diversas situações além da sala de aula.

De acordo com TOULMIN (2001) um discurso argumentativo possui um padrão e, se os elementos que compõem este padrão são válidos, então a estrutura completa do argumento também pode ser validada. O padrão de argumento de Toulmin pode ser ilustrado pela figura 1:

Figura 1: Diagrama ilustrativo da estrutura da construção argumentativa, padrão Toulmin.
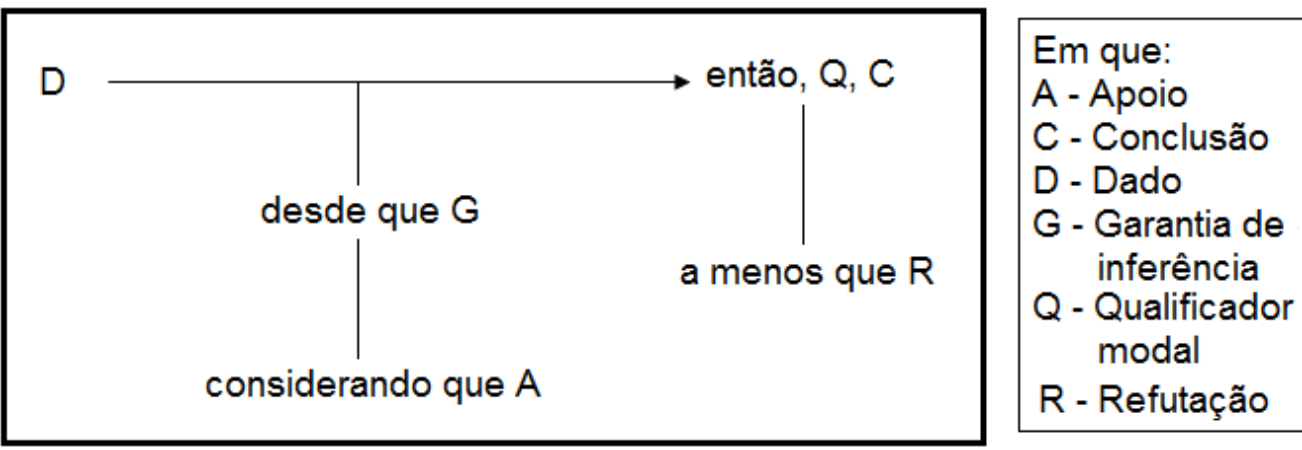

Fonte: TOULMIN, S. Os usos do argumento, 2001. 


\section{Ensino, Saúde e Ambiente - V 7 (1), Edição Especial, maio de 2014}

Dos seis elementos estruturais que compõem um discurso argumentativo, três são essenciais para a construção de um argumento válido, o dado (D) que é o conjunto sob os quais serão fundamentadas as afirmativas, a garantia de inferência $(\mathrm{G})$ que realiza a mediação entre o dado (D) e a conclusão (C) e a conclusão (C) que é a afirmação, o objetivo final do argumento. Apenas com esses três elementos já é possível estabelecer uma argumentação válida.

Os demais elementos propostos por Toulmin dão suporte e validade à construção do argumento. $\mathrm{O}$ apoio $(\mathrm{A})$ é um suporte dado à garantia de inferência $(\mathrm{G})$ com o intuito de reforçar a relação estabelecida entre (D) e (C), o apoio (A) pode ser, por exemplo, uma referência indiscutível como um axioma ou uma lei. O qualificador modal (Q) deve ser um elemento que confere uma maior confiabilidade à conclusão, uma referência externa ao próprio argumento a qual legitime a conclusão como correta. Por fim, a refutação $(\mathrm{R})$ estabelece as condições sob as quais o argumento possui validade. É a refutação que limita o poder do argumento quanto a suas condições de contorno, se a condição estabelecida pela refutação não for obedecida, então, o argumento não é válido e, em contrapartida, se as condições são satisfeitas, então, a garantia de inferência, junto com os outros elementos, garante a validade do argumento.

A estrutura de argumentação, da forma como foi apresentada, revela a estrutura argumentativa num monólogo, entretanto para que haja diálogo entre interlocutores alguns pressupostos devem ser observados. De acordo com BRETON (1996), para que um orador consiga expor seu argumento a um auditório de ouvintes, por exemplo, eles devem compartilhar, em boa medida, dos códigos utilizados na construção do argumento. Os elementos e fatos utilizados para validar o argumento do orador devem ser compartilhados pelo auditório, de forma que as conclusões estabelecidas pelos envolvidos no diálogo sejam as mesmas.

Isso ressalta a importância que deve ser destinada à linguagem utilizada durante uma argumentação, em sala de aula, por exemplo. A linguagem científica deve ser utilizada, mas a compreensão ficará prejudicada se os alunos não tiverem se apropriado dessa linguagem antes. Neste caso, quando os alunos não compartilharem dos mesmos códigos do professor, a argumentação, de forma unilateral (apenas do professor), poderá não produzir sentido para o aluno.

O estudo de caso a ser apresentado nesse artigo está também dentro de um campo de estudo que vem se desenvolvendo desde a década de 60 dentro do Ensino de Ciências, em especial no Ensino de Física, qual seja, a utilização da metodologia da 


\section{Ensino, Saúde e Ambiente - V 7 (1), Edição Especial, maio de 2014}

aprendizagem Baseada em Problemas (PBL). O crescimento desse campo de estudo está vinculado, de forma dialógica, com o aumento de pesquisas realizadas com esse enfoque. Em face dessa perspectiva, torna-se necessário compreender um pouco mais sobre essa abordagem que trata da resolução de problemas.

Tendo sua origem no Canadá, a metodologia PBL se difundiu rapidamente e alcançou algumas escolas Brasileiras no fim da década de 90. Não existem muitas escolas que adotam, em seu documento curricular, a postura metodológica PBL. Entretanto, de acordo com os $\mathrm{PCN}^{\mathrm{ee}} \mathrm{s}$, a resolução de problemas é um aspecto considerado importante no ensino de Ciências:

"A capacidade cognitiva tem grande influência na postura do indivíduo em relação às metas que quer atingir nas mais diversas situações da vida, vinculando-se diretamente ao uso de formas de representação e de comunicação, envolvendo a resolução de problemas, de maneira consciente ou não." (BRASIL, 1997, p. 47).

A habilidade de resolver problemas é requisitada no cotidiano de qualquer aluno, mais que desenvolver um conteúdo específico, a metodologia PBL visa a permitir que o aluno mobilize (a partir de uma situação problema) um conjunto de conhecimentos que são coexistentes na sua estrutura cognitiva. Dessa forma, podemos associar à aplicação da metodologia PBL a análise dos argumentos que aparecem naturalmente nesse ambiente de diálogo em sala. Vale ressaltar que, nesse tipo de abordagem metodológica, as respostas não devem ser oferecidas diretamente aos alunos, mas deve-se criar meios tais que o aluno se sinta provocado a encontrar as respostas por intermédio de uma prática pedagógica criativa.

\section{PERCURSO METODOLÓGICO}

Trata-se de um estudo de caso, de natureza qualitativa, em que foram adotados procedimentos de coleta de dados por meio da observação sistemática dos atores escolares e aplicação de instrumento do tipo questionário. A abordagem dos dados coletados seguiu numa linha interdisciplinar, e teve os conteúdos tratados conforme modelo proposto por Bardin. As aulas foram gravadas e posteriormente transcritas.

A classe participante é uma turma de primeiro ano de Ensino Médio Integrado ao Ensino Técnico em Automação Industrial de uma Escola Pública Federal, localizada no Estado do Rio de Janeiro. Essa sala apresenta um total de 37 alunos. Com a finalidade de conhecer as características etnográficas da turma, foi aplicado um semiestruturado para os educandos, sendo que, na ocasião, 32 discentes responderam ao 
mesmo. Durante a aplicação desse instrumento, ficou esclarecido aos alunos que não era necessária a identificação, que não se tratava de nenhuma espécie de teste ou avaliação de conhecimentos. Foi explicado à turma que era um questionário para um levantamento de dados e opiniões e que eles deveriam responder às perguntas sem se preocuparem em erros ou em acertos.

A média de idade dos alunos da turma é de 15 anos, aproximadamente, e, do total de alunos, 18 são do gênero masculino e 14 do gênero feminino, configurando-se uma turma que não apresenta grande hegemonia de um gênero especificamente, de forma que o gênero pode ser considerado, em boa medida, uma variável que pouco influenciaria a diferença entre os dados. Cabe salientar que esse número revela somente os alunos que responderam ao questionário, no dia em que o mesmo foi aplicado.

Quando perguntamos a todos os alunos se haviam estudado Física no Ensino Fundamental, apenas $12 \%$ responderam negativamente, o que mostra que, de alguma forma, a maior parte dos alunos já haviam tido contato com a Física como uma disciplina. Os alunos que responderam negativamente de certa forma também já tiveram contato com a Física, talvez não como um componente curricular distinto dos outros, mas dentro da disciplina Ciências. No sexto ano do Ensino Fundamental, por exemplo, um dos componentes curriculares de Ciências propõe o estudo do sistema solar, planetas e órbitas. Entretanto quando questionados sobre o estudo de Física, os alunos não conseguiram estabelecer essas relações. Isso é um aspecto importante a ser debatido, pois, muitas vezes, o Ensino de Ciências no Ensino Fundamental, por ser ministrado por um profissional das Ciências Biológicas, acaba sendo muito voltado para os assuntos da Biologia, não sendo trabalhado de forma interdisciplinar, como defendemos na atualidade, como um Ensino de Ciências interligando conhecimentos biológicos, físicos, químicos, entre outros. O convívio com os alunos, ao longo do tempo, foi revelando características das idiossincrasias da turma, as quais foram evidenciadas não somente por meio de questionários, mas da observação e da interatividade.

\section{A CONSTRUÇÃO DO DICIONÁRIO DA CINEMÁTICA}

Uma grande dificuldade encontrada no Ensino de Ciências, e de Física em particular, se encontra na diferença entre a linguagem cotidiana e a linguagem científica, para CHASSOT (2002, p.93) a ciência, em si, pode ser considerada uma linguagem. Muitas expressões utilizadas na cinemática não são do uso comum dos alunos, e outras 


\section{Ensino, Saúde e Ambiente - V 7 (1), Edição Especial, maio de 2014}

forma que os alunos fossem expondo suas idéias até serem conduzidos a um conceito mais preciso, em relação aos que eles já possuíam como senso comum.

Após discutir o conceito de referencial, foi lhes perguntado qual seria a melhor definição para "Repouso". A seguir apresentamos a ordem dos eventos, expressa pelos turnos abaixo. Cada fala representa um turno, nas quais, o professor aparece com a letra $P$ enquanto que os alunos são enumerados pela ordem de suas falas;

1. P: "Então... como vocês definiriam repouso... o que é um corpo estar em repouso para vocês?"

2. Aluno 1: "É não ter movimento ué..."

3. Aluno 2: "Estar parado..."

4. Aluno 3: "Em relação a um referencial... tem que ter um referencial..."

5. Aluno 2: "É... parado em relação a um referencial..."

Nesse trecho há um momento de silêncio, aparentemente à espera que o professor respondesse se as respostas estariam certas ou erradas.

6. $P$ : "E aí gente?... E então?..."

7. Aluno 4: "Tem haver com ficar na mesma distância... da referência..."

8. $P$ : "Será?..." [fala em tom de desafio]

9. Aluna 5: "Acho que não tem haver não..."

10. Aluno 4: "Tem sim...[ênfase na afirmação]... se a distância não mudar então é porque tá parado... repouso... né fessor...?"

Nesse ponto, os conceitos elaborados coletivamente por meio dos processos argumentativos dos alunos encontram uma situação de teste. Um dos alunos elabora um conceito de repouso, no qual, se não há mudança entre a distância entre o referencial e o objeto, não há movimento. Esse conceito esteve muito próximo do conceito final, entretanto como os alunos não conseguiam enxergar a falha nesse modelo, o professor fez uma intervenção com uma pergunta.

11. $P$ : “Então se a distância entre o referencial e o objeto não mudar então o objeto estará em repouso? É isso?... [um grupo de alunos responde que sim]. Então se um objeto se mover em um círculo, e o referencial for o centro do círculo a distância muda?... Significa que ele está em repouso?...”

Aqui, alguns alunos perceberam imediatamente que havia uma inconsistência naquele conceito de repouso, havia um caso que não era compatível com aquele modelo, o caso do movimento circular. Ao perceber tal inconsistência, os alunos que concordavam com o modelo experimentaram um obstáculo epistemológico 


\section{Ensino, Saúde e Ambiente - V 7 (1), Edição Especial, maio de 2014}

(BACHELARD, 2007). A partir desse momento, houve uma intenção de reestruturação dos argumentos. A dimensão argumentativa pode proporcionar ao aluno a comparação de seus conceitos prévios, do senso comum, com os conceitos elaborados pela ciência normal, é nesse contexto em que é mais provável mudança conceitual.

12. Aluno 2: "Então é estar parado... sem velocidade..."

13. Aluno 1: "É isso aí mesmo fessor... velocidade zero"

14. Aluno 4: "É quando a posição não muda... a posição, tipo, fica a mesma, em relação ao referencial..."

15. P: “Ah... e agora, será que é isso mesmo?... pensem no caso do movimento circular?... dá certo essa ideia?...”

16. Aluna 5: “Aí, sim, professor, agora se ficar na mesma posição é porque tá parado... como se ficasse num lugar só... aí tá em repouso...”

17. $P$ : "Então chegamos a uma definição melhor não é?... um corpo está em repouso em relação a um referencial, se a sua posição não muda em relação àquele referencial... „tá, aí, ó... vamos anotar esse, então..."

A conclusão sobre o conceito de repouso se tornou mais completa em relação ao conceito que os alunos elaboraram no turno 10, pelo fato de que a grandeza "distância" foi corretamente substituída pela grandeza "posição". Outro conceito que causa distorções na compreensão, que é a diferenciação entre intervalo de tempo $\Delta t$ e instante $t$, foi discutido de forma semelhante em sala. Podemos assumir que se esses conceitos, que possuem significações tão próximas, tivessem sido apenas apresentados aos alunos como definições, sem uma discussão dos seus significados e de seus sentidos, é provável que essas distorções conceituais tivessem ocorrido com maior frequência.

De acordo com BARDIN (2004) podemos categorizar um discurso quanto às suas semelhanças:

“A categorização é uma operação de classificação de elementos constitutivos de um conjunto por diferenciação e, em seguida, por reagrupamento segundo o gênero, com critérios previamente definidos." (BARDIN, 2004, p.147).

Para analisarmos os argumentos dos alunos podemos categorizá-los em dois grandes grupos: o primeiro, que relaciona o repouso com ausência de movimento, e o segundo, que relaciona o repouso com a não variação da distância. Dentro de cada uma dessas categorias, os alunos utilizam argumentos que, com o decorrer da discussão, vão se tornando mais consistentes. Os dois alunos dos turnos 2 e 3 , da primeira categoria de análise, iniciaram a discussão com argumentos muito simples, "é não ter movimento". 
Ensino, Saúde e Ambiente - V 7 (1), Edição Especial, maio de 2014

No turno 7, por exemplo ocorre a introdução de um novo elemento, da segunda categoria, o conceito de distância. A partir daí, os discursos convergem gradativamente para um ponto comum.

O EXPERIMENTO MRU - “O parafuso e a arruela - queda livre ou movimento uniforme?"

Essa experiência consistia em resolver um problema: determinar qual era o tipo de movimento de uma pequena arruela que era deixada cair livremente em torno de uma vara rosqueada e, se possível, determinar sua velocidade. Com um suporte, feito de madeira, colocou-se a vara rosqueada na vertical a arruela foi deixada cair livremente do ponto mais alto da vara rosqueada.

Foi perguntado aos alunos qual seria o tipo de movimento esperado quando abandonássemos a arruela. A maioria dos alunos respondeu que a arruela desceria com um movimento muito parecido com o de uma de queda livre. Entretanto, não foi isso que aconteceu: ao deixar cair a arruela ela executou um movimento muito similar a um movimento uniforme à primeira vista, com uma velocidade média bem inferior em relação à velocidade que teria atingido em queda livre. Nesse ponto, os alunos foram questionados se conseguiriam resolver esse problema.

1. $P$ : "E, aí, gente, como vamos resolver esse problema? O que tem que fazer pra saber que movimento é esse? É MRU ou MRUV? Tem que fazer o quê?"

2. Aluna 6: "é só medir o comprimento do parafuso e dividir pelo tempo?...”[vários alunos falam]

Entretanto esse método serviria apenas para calcular a velocidade média no percurso, e não para determinar se o movimento era, ou não, acelerado, o que mostra que houve uma compreensão sobre velocidade média, mas não o suficiente para utilizar a equação em uma situação problema real. A compreensão da turma não foi suficiente para fazê-los diferenciar MRU de MRUV.

De acordo com BAKHTIN (1979/2003), as produções discursivas e argumentativas de um indivíduo são construídas a partir do seu contexto social e histórico, desse ponto de vista, podemos ressaltar que as opiniões emitidas pelos alunos, acerca da previsão do movimento da arruela, estão ligadas a suas experiências de vida e observações cotidianas. Como eles já haviam sido apresentados às equações do MRU e 
MRUV, anteriormente a essa experiência, eles utilizaram esse elemento (da equação de velocidade média) para responder à pergunta inicial.

3. $P$ : “Ué, mas se agente deixar a arruela cair livremente, pegar a distância e dividir pelo tempo, só isso daria pra saber se o movimento é MRU ou MRUV, gente?”

4. Aluno 4: "não"

5. Aluno 1: "não"

6. Aluna 6: "só vai saber a velocidade..."

7. $P$ : "E aí faz o que então? Tem que resolver o problema..."

8. Aluno 4: "faz um monte de vezes e vê se dá tudo parecido"

9. $P$ : "Medir tudo igual, várias vezes? Mas não daria no mesmo?"

10. Aluno 4: "não, não medir tudo não, medir um pedaço de cada vez só... entende?.. para ver se fica o mesmo movimento..."

Nesse ponto, começou a fazer sentido para os alunos que, para que um movimento seja categorizado como MRU, o móvel deve percorrer espaços iguais em mesmos intervalos de tempo. A partir desse ponto, ficou fácil perceber que, colocando uma trena ao lado da vara rosqueada, e anotando o tempo em intervalos iguais de distância, poderíamos observar se o movimento era ou não uniforme e, ainda, calcular sua velocidade média.

Podemos identificar no argumento do aluno 4, no turno 10, uma ideia que fundamenta o conceito de velocidade instantânea. A velocidade instantânea pode ser calculada como a taxa de variação da posição de um móvel num intervalo de tempo $\Delta t$ infinitesimal, no limite em que $\Delta t$ tende a zero, como mostra a equação 1.

$$
\lim _{\Delta t \rightarrow 0} \frac{\Delta S}{\Delta t}
$$

O procedimento foi realizado pelos educandos da seguinte maneira: eles se revezaram nas medições, a sala foi dividida em grupos de sete alunos, cada qual era responsável por três medições e preencher uma tabela semelhante à tabela 1. A introdução da tabela serviu para sistematizar os dados. Vale ressaltar que a estruturação da tabela foi apenas orientada pelo professor, os alunos tiveram que pensar de que forma os dados seriam estruturados, já que as tabelas não estavam prontas previamente. 
Ensino, Saúde e Ambiente - V 7 (1), Edição Especial, maio de 2014

Tabela 1: Exemplo de tabela de um grupo de alunos com valores das medidas do experimento

\begin{tabular}{|l|l|l|l|}
\hline Medição & Espaço percorrido $(\mathbf{c m})$ & Intervalo de tempo $(\mathbf{s})$ & $\mathbf{V}_{\mathbf{m}}$ no intervalo $(\mathbf{m} / \mathbf{s})$ \\
\hline $\mathbf{1}$ & 15 & 4,3 & 3,5 \\
\hline $\mathbf{2}$ & 15 & 5,2 & 2,9 \\
\hline $\mathbf{3}$ & 15 & 4,9 & 3,1 \\
\hline MÉDIA & & & $\mathbf{3 , 2}$ \\
\hline
\end{tabular}

A figura 3 mostra o momento em que foi feita uma medição como exemplo para ilustrar o experimento:

Figura 3: alunos durante a execução do experimento

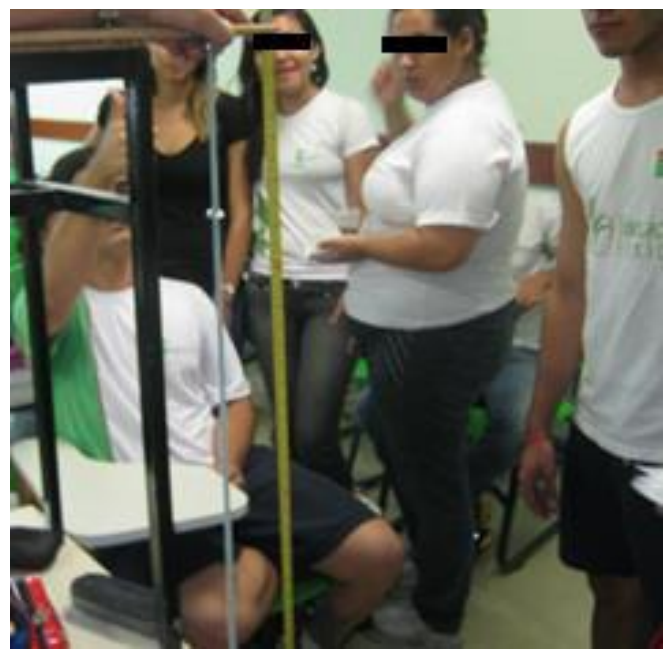

Fonte: autor, 2013.

\section{CONSIDERAÇÕES FINAIS}

Os episódios apresentados permitem a percepção que, ao utilizar uma metodologia de ensino baseada em problemas, é possível abrir caminho para a argumentação no processo de aprendizagem, concitando a participação do aluno.

Ouvir e considerar o conhecimento prévio dos alunos, identificando suas eventuais estruturas conceituais e modelos, pode ajudar a desenvolver o aprendizado de novos conceitos e aperfeiçoar os conceitos de senso comum dos alunos.

Além de tornar o processo de aprendizagem mais democrático, a análise dos argumentos elaborados pelos alunos, durante as aulas, mostrou-se importante para a realização da avaliação conceitual. Em várias situações, as falas dos alunos explicitaram modelos conceituais que possivelmente não seriam percebidos sem uma dinâmica de diálogo em sala de aula. Esses modelos conceituais podem ser utilizados como ponto de partida para uma aproximação conceitual mais segura na construção do conhecimento científico. 


\section{Ensino, Saúde e Ambiente - V 7 (1), Edição Especial, maio de 2014}

É importante salientar, também, que o professor que utiliza esse tipo de metodologia, em sua práxis cotidiana, deve atentar para nunca fornecer respostas prontas para os alunos. É importante sempre instigá-los, no intuito de promover, e aguçar, sua curiosidade para que busquem formas alternativas para responderem aos questionamentos propostos. A cada pergunta dos alunos, o educador pode responder com outro questionamento, para que o aluno consiga pensar e construir, desconstruir e reconstruir o seu próprio conhecimento, tornando, dessa maneira, a aprendizagem mais significativa. Além disso, os problemas utilizados em sala de aula devem estar de acordo com a faixa etária e cognitiva dos discentes e de acordo com a sua realidade histórica e social, para que os mesmos se sintam estimulados a participarem ativamente da resolução dos problemas práticos apresentados.

\section{REFERÊNCIAS}

BACHELARD, G. Estudos. São Paulo: Contraponto, 2007

BAKHTIN, M. M. Os gêneros do discurso. Estética da criação verbal. Trad. Paulo Bezerra. São Paulo: Martins Fontes, 2003.

BARDIN, L. Análise de conteúdo, 3. Ed. Lisboa: Edições 70, p.147, 2004.

BRASIL, Secretaria de Educação Fundamental. Parâmetros Curriculares

Nacionais: Ciências Naturais. Secretaria de Educação Fundamental. Brasília (DF): MEC/SEF, 1997.

BRETON, P. A argumentação na comunicação. 1 Ed. Bauru. SP, EDUSC, 1999. (Tradução do original francês L'argumentation dans la communication, Paris,1996).

CHASSOT, A. Alfabetização científica: uma possibilidade para a inclusão social. Revista Brasileira de Educação nº 21, set./dez, p. 157-158. 2002.

MORTIMER, E. F. e MACHADO, A. H. Múltiplos olhares sobre um episódio de ensino: "Por que o gelo flutua na água?". Encontro sobre teoria e pesquisa em Ensino de Ciências. Belo Horizonte, 1997.

NASCIMENTO, Silvana S.; VIEIRA, Rodrigo D. Contribuições e Limites do Padrão de Argumento de Toulmin Aplicado em Situações Argumentativas de Sala de Aula de Ciências, Revista brasileira de pesquisa em Educação em Ciências, v. 8, n.2, 2008.

VILLANI, C. E. P. As práticas discursivas argumentativas de alunos de ensino médio no laboratório didático de física. Dissertação de mestrado: Faculdade de educação, UFMG, 2002.

TOULMIN, S. Os usos do argumento. Trad. R. Guarany, Martins Fontes, São Paulo, 2001. 